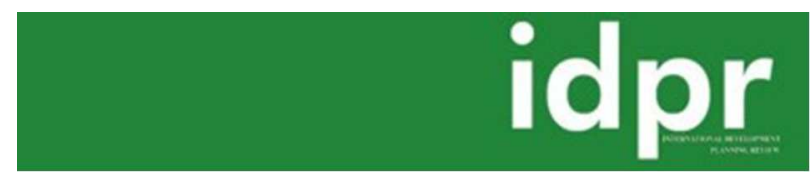

\title{
Planning for climate change in the African city
}

\begin{tabular}{|c|l|}
\hline Journal: & International Development Planning Review \\
\hline Manuscript ID: & IDPR-14-0018.R1 \\
\hline Manuscript Type: & Viewpoint \\
\hline Keywords: & planning, climate change, adaptation, Africa, experimentation \\
\hline Abstract: & $\begin{array}{l}\text { In this viewpoint I argue for a perspective that, looking at climate change } \\
\text { in African cities, focuses both on challenges and opportunities for } \\
\text { action. Delivering climate change adaptation in cities is most often akin to } \\
\text { addressing immediate infrastructure and service provision needs, because } \\
\text { increasing climate change resilience in cities also requires improving the } \\
\text { delivery of services to all citizens. However, there is a risk that climate } \\
\text { change discourses facilitate the deployment of technocratic, expert-led } \\
\text { forms of planning, particularly when climate change is used as an excuse } \\
\text { to facilitate the intervention of international planning consultants who most } \\
\text { often know little about the local context of planning. This paper advocates } \\
\text { instead for approaches to climate change action that harness opportunities } \\
\text { on the ground engaging with the creative potential that urban citizens } \\
\text { already have and drawing attention to the need to develop planning skills } \\
\text { from within the city. }\end{array}$ \\
\hline
\end{tabular}


1

2

3

4

5

6

7

8

\title{
Planning for climate change in the African city
}

\author{
Vanesa Castán Broto \\ Development Planning Unit \\ Bartlett Faculty of the Built Environment \\ University College London \\ 34 Tavistock Square London \\ email: v.castanbroto@ucl.ac.uk
}

Viewpoint for the International Development Planning Review

Wordcount: 3406 words

Liverpool University Press

\begin{abstract}
In this viewpoint I argue for a perspective that, looking at climate change in African cities, focuses both on challenges and opportunities for action. Delivering climate change adaptation in cities is most often akin to addressing immediate infrastructure and service provision needs, because increasing climate change resilience in cities also requires improving the delivery of services to all citizens. However, there is a risk that climate change discourses facilitate the deployment of technocratic, expert-led forms of planning, particularly when climate change is used as an excuse to facilitate the intervention of international planning consultants who most often know little about the local context of planning. This paper advocates instead for approaches to climate change action that harness opportunities on the ground engaging with the creative potential that urban citizens already have and drawing attention to the need to develop planning skills from within the city.
\end{abstract}




\section{Planning for climate change in the African city}

'... our starting point is the African experience itself.'

(O’Connor, 2007[1983]; p. 23)

\section{Introduction}

In a recent viewpoint in IDPR David Simon (2014) has argued for an engagement with development planning to address climate change at the local level. Planners have been called to take a leading role in addressing climate change in cities through the development of plans, priorities and valuations but the extent to which these approaches can or should be applied in African cities is overlooked (e.g. Wheeler, Randolph et al. 2009). This is so despite exemplar attempts to integrate climate change in municipal policy in cities such as Durban (Roberts 2008) and Cape Town (Mukheibir and Ziervogel 2007, Cartwright, Parnell et al. 2012). As Simon (2014) explains, funding constraints have directed efforts away from actions addressing climate change in favour of other development needs that are perceived to be more urgent.

What does planning for climate change mean in Africa? Climate change calls for solutions tailored to specific contexts because of the heterogeneity of climate change impacts and vulnerability factors, and the multiple possibilities to address them (Simon 2010). In relation to development challenges, effective climate change adaptation requires 'a competent, capable local government that is able and willing to work with the inhabitants of the settlements most at risk' (Dodman, Bicknell et al. 2012; p. 362). But planning, for long, has undelivered- to say the least- in Africa. The absence of good forms of planning has led to a situation in which 'planning systems are relics of colonial days, and cities suffer from failed attempts by international aid and development agencies to address urban issues through development models based on assumptions that rarely hold in this 
part of the world' (Parnell, Pieterse et al. 2009; p. 233). It would appear that climate change only adds further hardship to an already sorry situation of planning in African cities. As Simon (2014) argues, there is a need to engage with positive contributions that can address both concerns about climate change and the development needs of cities in Africa.

\section{Towards addressing climate change in cities}

There are growing calls for practical alternatives to address climate change beyond the international negotiations that take place in the annual Conference of Parties (COP) under the auspices of the United Nations Framework Convention for Climate Change (UNFCCC) secretariat. In the COP, negotiators work against impossible deadlines into the early hours of the morning and an atmosphere of pessimism reigns. As the COP begins disaster strikes once more, this time (November 2013) in Philippines. Walking the conference corridors, the visitor is welcomed by a gallery of exhausted people, napping and relaxing in any available sofa, speaking frenetically over lunch, slipping out into side events as if searching some unexpected illumination and running back to the negotiation forums. As deals are achieved over apparently minor details unintelligible to those who do not dedicate their full attention to the negotiations, the UNFCCC secretariat insists on progress being made.

For those like me who have observed with impatience the sluggish process of international negotiations (and wondered about its relevance on the ground) cities have emerged as fertile grounds for climate change action (e.g. Bulkeley and Betsill 2003). Cities offer opportunities for climate-conscious intervention, not just because of the concentration of activities that can be linked to greenhouse gas (GHG) emissions and to climate change vulnerabilities in urban centres, but also, because cities offer opportunities for direct intervention against climate change (UN-Habitat 2011). Much focus has gone towards local authorities who have responsibilities for service provision, land management and disaster preparedness and thus, take decisions on a daily basis that can influence both GHGs emissions and vulnerability factors (e.g. Allman, Fleming et al. 2004, Romero Lankao 
2007). More recently, however, empirical evidence has shown that local authorities intervene in partnership or alongside a range of other urban actors capable of shaping governance processes to deliver climate change action (Bulkeley and Castán Broto 2013). The city becomes a site for multiscalar collaboration, fostering the kind of cooperation that in the long term can deliver flexible institutions to respond to the uncertainties inherent to climate change (Leck and Simon 2013). From this perspective climate change action is not limited to rich cities having resources and capacities, but rather, takes place in different contexts through the interaction of actors operating at multiple scales and harnessing a variety of international, national and local resources. The extent to which the impact of such actions is transformative depends on the particular manner in which climate change action takes place. Moreover, this variety of activities and actors shapes narratives of how climate change governance is or ought to be. During the last two COPs, for example, the UNFCCC secretariat has recognised the importance of punctual initiatives against climate change through their program Momentum for Change, celebrating such initiatives as 'Lighthouse Activities', with a dedicate pillar for actions that benefit the urban poor. They argue that localised initiatives such as these may have practical implications even if their results are not directly measurable in terms of risk or emissions reductions. Efforts to recognise the value of localised, experimental action constitute a call for optimism, optimism that can enable forms of cooperation beyond the formal strictures of government regulations and plans.

Nowhere is the marked contrast between government strategy and practical action more visible than in Africa. In my work during the last two years in Maputo, Mozambique, I have encountered an institutional discourse deeply engaged with climate change that has led to the production of different plans and assessments by international and national organisations (for a review see Castán Broto, Oballa et al. 2013). Simultaneously I have seen limited efforts to link such discourses both to ongoing actions to improve the lives of urban citizens (for example by coupling plans with slum upgrading projects) or to rethink the existing deficient systems of provision and the way they are 
shaped by current structures of urban governance. In Maputo, officials both at the municipal level and at the neighbourhood level emphasise relocation as the central strategy to address climate change risks in informal settlements, despite the obvious difficulties both in terms of the viability of these plans and the terrible impacts for those who are to be relocated. Investments in disaster risk reduction concentrate in the old colonial city, where most affluent citizens and international business are. Mozambique authorities have produced and sponsored plans, assessments and strategies but there is little action visible on the ground that could be directly linked back to such plans. Such climate change plans are often written following international guidance, by external consultants and with reference to assessments and methods developed in extraneous contexts that hardly reflect the context of urban governance in Maputo. Plans are indeed developed without full consideration of the extent to which such plans are limited both to make a diagnosis of the current situation and to provide a framework that will enable effective action in that particular context. This seems to reproduce the modus operandi of international planning consultants in conceptualising and simplifying the African city. Yet, if there is something inherently true to 'the African city' is that it resists characterisation and simplification in the manner demanded by Western-based rationalities. Climate change only exacerbates the mismatch between planners' sketches of the city and its actual dynamics.

\section{Climate change and development planning}

In many African cities the urban governance context is changing rapidly in response to the concerns emerging from international climate change debates. First, climate change is a field that requires engagement with complex information only available to individuals with advanced expertise, whether this is in relation to understanding the significance of global circulation models in specific urban contexts, the selection of an ever-changing landscape of climate change technologies or the access to the complex world of climate change financing. Much capacity is required not just to engage in complex climate change negotiations, but also to develop plans that can relate to 
appropriate actions on the ground. Second, because of the increasing circulation of carbon reduction and climate change adaptation finance, climate change provides the grounds for concrete interventions in disaster risk reduction and service provision at the local level, but this requires expertise in the fields of climate change as explained above. So far, there has been an emphasis on expert-led planning in international approaches to climate change, particularly in terms of providing common grounds for negotiation through, for example, instruments such as the National adaptation programmes of action (NAPAs) for the identification of priorities in Least Developed Countries (LDCs) supported by the UNFCCC secretariat through the Global Environmental Facility. At the local level climate change planning has meant an overall focus on targets and measures and a decided emphasis on attaining low hanging fruits or bring together ongoing activities under the banner of climate change. Overall, climate change has been characterised as 'one issue in which lengthy participatory planning is not appropriate and that instead, rapid, top-down action may be necessary to begin to reduce emissions or prepare for potential climate-related disasters' (Blanco, Alberti et al. 2009).

In practice, this has also meant the raise of the international climate change consultant in city planning. The Municipality-endorsed report on climate change in Maputo for UN-Habitat's programme Cities and Climate Change Initiative (CCCI) was carried out by the international development consultancy Agriconsulting S.p.a. and the Istituto di Biometeorologia - Consiglio Nazionale delle Ricerche, both based in Italy. The second phase report of the Institute for Disaster Risk Management of Mozambique (INGC), elaborated as well by a disparate team of experts, recommended among other things the creation of a climate knowledge centre to be modelled upon and supervised by expert-based centres of excellence such as the South African Environmental Observation Network, the UK-based Tyndall Centre for Climate Change Research, and the German network of research organisations Fraunhofer. Consultants have had a key role in assessing the risks of climate change and bringing to fruition global circulation models in a local setting. This is 
not specific to Maputo and Mozambique, of course. From Turkey to the India, from the Middle East to Namibia, international planning consultants are bringing master planning to new depths, engaging with the creation of new cities such as Masdar and the physical reinvention of old ones such as Istanbul. Sustainable technologies and concepts such as compact city and biomimicry (e.g. Head 2009) are central to this work which remains, in essence, a top-down model of urban intervention that looks more towards internationally produced forms of knowledge by a cosmopolitan class of experts than towards local contexts of intervention. International consultants are often seen to bridge separate scales between the global production of knowledge about climate change and the local application of concrete measures. They are also able to quantify impacts of proposed urban futures and thus, they can access climate finance. The extent to which the work of international planning elites is in consonance with international finance ones- especially those dedicated to mastermind the brave new world of carbon trading- is not clear, but what is clear is that both are able to harness climate change expertise to deploy planning and financial interventions at the urban scale. For local and national governments, already overwhelmed by their lack of capacity to provide basic services, and for people living in cities whose history automatically privileges minorities over the impoverished majority, climate change only opens up opportunities if they are able to enrol these international forms of expertise that control climate change opportunities.

To what extent this amounts to progressive action towards improving the wellbeing of urban residents, addressing urgent urban health issues and reducing people's vulnerabilities to climate change? This is akin to asking the extent to which action against climate change actually responds to citizens' needs. Since we lack a crystal ball to look into the future, asking citizens what their actual needs are is our best chance to get it right. Through small initiatives, such as those highlighted by the UNFCCC Momentum for Change programme, intervention opens up political debate. Different actors may see their actions legitimated and may challenge dominant interpretations of what climate change means in an urban context. In doing so, they challenge 
attempts to move towards a technocratic landscape of urban governance under the threat of climate change. Localised forms of experimentation demonstrate the city's resistance to planning constrains and regulatory categorizations, revealing instead a dynamic context in which top down attempts to implement climate action are confronted with the realities on the ground. To the extent that these initiatives may emerge from within citizens groups and communities, they represent an opportunity to engage with climate change differently: an alternative to the dominance of international elites of academics, finance experts and consultants in climate change debates at the local level.

\section{Addressing the challenge in African cities}

What are the implications for planning for climate change in the African city? The attempt to subsume heterogeneity under the phrase 'the African city'- as if there was just one of them, rather than multiple cities and then, multiple cities within any single city- points towards a problematic which enables generalisation. This is the extent to which planning in urban Africa has been shaped by external forces in a way that has prevented the development of endogenous forms of planning and management, and thus, has led to a mismatch between attempts at planning and the realities on the ground. Talking about 'the African city' is a strategy both, to highlight the weight of postcolonial heritage in urban Africa and, from this vantage point, to insist in the need for perspectives that emerge from within and characterise the African city in dialogue, but not subject to, paradigms that emerge from other urban contexts (Parnell, Pieterse et al. 2009). Talking about 'the African city' is directed towards questioning blanket assessments that portray cities in Africa as a dystopia. It reminds the theorist, the planner and the expert that cities in Africa are not empty, underdeveloped containers waiting for old paradigms to be deployed and that the lacks in cities in Africa are not related to lack of resources and capacity as much as they are related to the manners in which these are deployed. We need affirmation that cities in Africa are not necessarily examples of 'all that can go wrong with urbanism'; that instead, they are sites where people go about their life and take whatever steps are possible to improving it (Myers 2011; p. 3-4). 
The lack of African-specific planning perspectives is coupled with a general shortage of professionals and limited possibilities to improve the situation because of an outdated system of planning schools (for a devastating analysis see: Odendaal 2012, Watson and Odendaal 2013). Thus, urban scholars in Africa- or those interested in Africa- face now 'an urgent need to formulate new approaches and ideas which are grounded in the realities of urban settlement in Africa'(Parnell, Pieterse et al. 2009; p. 233). Such approaches will need to recognise both the realities of citizens making a living in any such African city (Simone 2010) and the difficulties faced by city planners and decision makers. O'Connor's (2007 [1983]) view on cities in Africa as being 'in the making' highlights the importance to look at the city as an open experience, one in which city actors are constantly experimenting (Simone 2004).

What does this mean for climate change? First, it means that planning in Africa should not shy away from climate change as a crucial issue that may have an impact on peoples' lives; second, it means that agendas for climate change adaptation need to be integrated and developed with parallel agendas for disaster risk reduction, service provision and sustainable development; third, it means that when local residents engage with these general concerns they are able to identify immediate proposals that can address such concerns simultaneously (in Maputo for examples, residents in the neighbourhood of Chamaculo $\mathrm{C}$ asked for: drainage cleaning; sustainable waste management and recycling; repairing water pipes); and fourth, it means that- rather than position themselves to take advantage of a promise of carbon finance that may not reach local governments or citizens- city governments should be working across scales to build networks enrolling citizens, civil society and the private sector to start working towards practical actions on the ground. The impact of experimental actions for climate change may not always be measurable, but experimentation may have the potential to transform societies through the reinvention of institutional and material networks (Bulkeley and Castán Broto 2013).

There is not a silver bullet that will solve at once all the issues of service provision, poverty, socio- 
economic inequality, disaster vulnerability and climate change. Thinking about climate change

experimentation, about practical action on the ground, about opportunistic partnerships between concerned actors does not speak to well-planned transitions to climate resilient, sustainable cities.

We do not know how radical is the transformation required to address climate change challenges and how it could come about. It could come from a group of local residents organising themselves to clean their own drainage and helping redesign disaster management institutions. It could come from a government organisation enabling partnerships between private providers and residents to manage waste sustainably. We don’t know. That is why we have to keep trying to take whatever opportunity for change we glance at that could bring a better future for all citizens. Even in African cities.

\section{References}

Allman, L., P. Fleming and A. Wallace (2004), 'The progress of English and Welsh local authorities in addressing climate change', Local Environment: The International Journal of Justice and Sustainability, 9(3), 271 - 283.

Blanco, H., M. Alberti, R. Olshansky, S. Chang, S. M. Wheeler, J. RandolPh, J. B. London, J. B. Hollander, K. M. Pallagst, T. Schwarz, F. J. PopPer, S. Parnell, E. Pieterse and V. WATSON (2009), 'Shaken, shrinking, hot, impoverished and informal: Emerging research agendas in planning', Progress in Planning, 72(4), 195-250.

Bulkeley, H. and M. M. BeTsiLl (2003), 'Cities and Climate Change: Urban Sustainability and Global Environmental Governance', Oxon, NY, Routledge.

Bulkeley, H. and V. CASTÁN BROTO (2013), 'Government by experiment? Global cities and the governing of climate change', Transactions of the Institute of British Geographers, 38(3), 361-375. CARTwright, A., S. PARnell, G. OElofSE and S. WARD (2012), 'Climate Change at the City Scale: Impacts, Mitigation and Adaptation in Cape Town', Abingdon, Routledge.

CAstán Broto, V., B. OBAlla and P. Junior (2013), 'Governing climate change for a just city: challenges and lessons from Maputo, Mozambique', Local Environment, 18(6), 678-704.

Dodman, D., J. Bicknell and D. SATTERTHWAite (2012), 'Adapting Cities to Climate Change: Understanding and addressing the development challenges', Abingdon, Routledge.

HEAD, P. (2009), 'Entering an ecological age: the engineer's role', Proceedings of the ICE-Civil Engineering, Thomas Telford, 162, 70-75.

LECK, H. and D. SIMON (2013), 'Fostering multiscalar collaboration and co-operation for effective governance of climate change adaptation', Urban Studies, 50(6), 1221-1238.

MukHEIBIR, P. and G. ZiERVOGEL (2007), 'Developing a Municipal Adaptation Plan (MAP) for climate change: the city of Cape Town', Environment and Urbanization, 19(1), 143-158.

Myers, G. A. (2011), 'African cities', London, Zed Books

O'Connor, A. (2007 [1983]), 'The African City', Abingdon, Routledge. 
OdEndAAL, N. (2012), 'Reality check: Planning education in the African urban century', Cities, 29(3), 174-182.

PARnell, S., E. Pieterse and V. WATSON (2009), 'Planning for cities in the global South: an African research agenda for sustainable human settlements', Progress in Planning, 72(233-241).

ROBERTS, D. (2008), 'Thinking globally, acting locally-institutionalizing climate change at the local government level in Durban, South Africa', Environment and Urbanization, 20(2), 521-537. RoMERo LANKAO, P. (2007), 'How do Local Governments in Mexico City Manage Global Warming?', Local Environment: The International Journal of Justice and Sustainability, 12(5), 519 535.

SIMON, D. (2010), 'The challenges of global environmental change for urban Africa', Urban Forum, $21,235-248$.

SimON, D. (2014), 'New Evidence and Thinking on Urban Environmental Change Challenges', International Development Planning Review, 36.

SimONE, A. (2004), 'People as infrastructure: intersecting fragments in Johannesburg', Public Culture, 16(3), 407-429.

Simone, A. (2010), 'City life from Dakar to Jakarta, Routledge, New York. UN-HABITAT (2011), '2011 GRHS Cities and Climate Change', London Earthscan. Watson, V. and N. OdendaAl (2013), 'Changing Planning Education in Africa The Role of the Association of African Planning Schools', Journal of Planning Education and Research, 33(1), 96107.

WHEELER, S., J. RANDOLPH and J. LONDON (2009), 'Planning and climate change: an emerging research agenda', Prog in Plan, 72, 195-250. 